\title{
THE OPERATIVE TREATMENT OF FRACTURES
}

\author{
From Mr William Gissane, Birmingham, ENgland
}

To the Editor,

Journal of Bone and Joint Surgery.

DEAR Sir,

Mr J. C. Scott (Journal of Bone and Joint Surgery, 33-B, 508, 1951), writing in meditative mood, and with the detached approach characteristic of some orthopaedic surgeons towards our responsibility for the treatment of acute injury, deplores " the tendency in the last twenty. years to a great increase in the operative treatment of fractures." His choice of trochanteric fractures to illustrate his thesis is unfortunate for his results compare very unfavourably with the carefully documented evidence of this hospital's practice (Evans, E. M., Journal of Bone and Joint Surgery, 31-B, 190, 1949; and 33-B, 192, 1951).

The difference in the quality of results, truly recorded from both sources, cannot be attributed to any difference in technical ability. We have evidence from other able surgeons elsewhere, who follow the operative method, that they cannot match our figures. The reason is that they lack our facilities.

We believe that the superiority of the operative method rests upon an emergency approach; the more fragile and aged the patient the greater the emergency in terms of hours not days. To delay operation for three to four days (Mr Scott's average) is, in our view, to court pulmonary complications with an inevitable increase in morbidity and mortality rates.

The emergency approach to the operative treatment of certain closed fractures necessitates an essential basic organisation; sufficient hospital beds, operating theatres immediately available with first-class radiological services, good anaesthetists and competent surgeons on emergency call, and laboratory facilities to provide carefully matched blood. We have found blood transfusion particularly useful in tiding feeble old ladies over emergency operations.

$\mathrm{Mr}$ Scott's reasons for the increase in the operative treatment of all closed fractures are valid but we would like to see them more soundly based. Closed fractures are wounds frequently associated with extensive soft tissue injury and always attached to patients with specific and individual requirements. The extent of the soft tissue injuries can be assessed, with fair accuracy, by clinical examination under anaesthesia, provided this examination takes place before blistering, oedema, blood extravasation and clotting have hidden the clinical picture. This examination together with the $\mathrm{x}$-ray evidence of the pattern of the fracture enables us to decide upon the advisability of closed manipulative reduction as against immediate open reduction.

Visual examination of fractures opened within a few hours of injury gives a remarkably clear picture of the nature and complexity of the wound that must be healed. Only at this stage is each component easily recognised-stripping and displacement of periosteum and muscles, tears of fascia, essential ligaments and joint capsule, the presence of loose displaced fragments in joints or preventing the stability of fracture reduction. It is essential to place the skin incision over the "open " side of the fracture wound and to respect and retain the soft tissues on the "hinge" (Charnley, J., The Closed Treatment of Common Fractures. E. \& S. Livingstone Ltd., 19:0) or " closed" side of the fracture. It is our impression that early open reduction, well carried out on selected fractures, expedites healing and lessens post-fracture oedema, by fulfilling the fundamental requirements of all wounds-that torn and displaced tissues shall be approximated and held at rest until healing occurs.

If, on a nation wide scale, orthopaedic surgery is to lead these advances in the treatment of fractures, there must be provided the essential basic facilities and team surgery on an

vol. $34 \mathrm{~B}$, No. 2, MAY 1952 
emergency scale not yet considered as essential to the hospital services of this country. Mr Scott's essay implies an acceptance of the status quo. This hospital's practice does not accept his thesis or the argument he has used to support it.

Our own surgical practice is a dangerous one to follow without the essential background. Yet to demand these facilities is not a new conception. Fifteen years ago, the late R. C. Elmslie-a former president of our Association-giving evidence before an interdepartmental committee (Final Report of the Inter-Departmental Committee on Rehabilitation of Persons Injured by Accidents. London: H.M.S.O., 1939) on behalf of our Association, advocated the establishment of a " small number of large and highly efficient clinics in this country for the treatment of accidents." After eleven years' experience the Birmingham experiment supports his view. The treatment of fractures represents no more than 30 per cent of the surgical problems involved in accidents, but they can be handled at the same tempo and with the same skill as surgical shock, multiple injuries, open wounds and severe burns, about which it is not necessary to plead for adequate facilities.

On the specific issue of trochanteric fractures our service has been called upon to answer a difficult social problem in a large city-following the conservative method we could not even keep pace with it. With the operative method we have not only been able to meet all responsibilities but we have lessened our morbidity and mortality rates. This is the final test that Surgery must answer with all injuries.

Sir, I regret having answered a sermon with a sermon, but the issue between two schools of thought in the treatment of injuries is now fairly joined.

Yours truly,

January 31,1952 .

WILLIAM GISSANE.

From Mr J. C. Scott, Oxford, England

To the Editor,

Journal of Bone and Joint Surgery.

DeAR Sir,

I appreciate the opportunity you have given me to comment on the letters by Mr Mervyn Evans and Mr Gissane to be published in the May number of the Journal. I consider that Mr Mervyn Evans has made one of the most valuable and best documented contributions to this subject. The use of the word " fallacious" does not impute any lack of good faith or inaccuracy in reporting. Deception in medical writings arises more often from enthusiasm than any other single cause, and my suggestion was that papers were in support of one method or the other rather than attempts at dispassionate comparison of the two methods.

I failed to make a useful statistical comparison of the methods because I decided, after doing a relatively small number, that it was not right to continue to use the " alternate" method of selection.

Mr Mervyn Evans admits selection of cases. Scarce beds were found for " good operative risks " but not "if the patient was very old and feeble." If the twenty-five patients, with an average age of seventy-seven and a mortality rate of 44 per cent, who were turned away because there was no bed, had been admitted the mortality rates would have been quite different. In fact if these deaths were added in equal numbers to the operative and conservative series the mortality rate would be approximately 20 per cent in both groups. If they had all been operated on, as Mr Mervyn Evans recommends, the mortality rate in the operation series would probably have been higher. No mention is made of how many patients were 